\title{
Reliability of concrete columns under vehicle impact
}

\author{
D. Mestrovic ${ }^{1}$, D. Cizmar $^{1}$ \& L. Miculinic ${ }^{2}$ \\ ${ }^{1}$ Faculty of Civil Engineering, University of Zagreb, Croatia \\ ${ }^{2}$ Graduate student at Faculty of Civil Engineering, University of Rijeka, \\ Rijeka
}

\begin{abstract}
As many actions on bridges are well known and easily determined, problems arise in the modeling of accidental situations such as the impact of vehicles on a bridge substructure. European regulation EN 1991-7 provides strategies and rules for safeguarding buildings and other civil engineering works against identifiable and unidentifiable accidental actions. This article will focus on vehicle impact on concrete columns. European regulations recommend minimum equivalent static design forces due to vehicular impact on members supporting structures over roadways. The value of this force is dependent only on the type of road (speed and mass of vehicle) and height of the impact. This kind of calculation is deterministic and in principle can't take into account all the uncertainties that arise prior to and during vehicular impact with a concrete column. The impact probability, angle of the collision curse, vehicle velocity, vehicle mass and stiffness (actions on the column), the material and geometrical properties of the column (resistance of the column) are modeled in a probabilistic manner and the probability of failure is analyzed. This article will compare deterministic and probabilistic modeling of vehicle impact. It is concluded that deterministic modeling of vehicle impact can largely underestimate actions (forces) on columns during impact.
\end{abstract}

Keywords: impact force, probabilistic, reliability.

\section{Introduction}

All actions on structures are, in principal, probabilistic in their nature. However, we can state that some of the actions are well known and relatively easily 
determined (dead load, traffic load, prestressing loads etc), on the other hand this is not true for wind, earthquake and impact loads, for example. As of today all building codes are deterministic is essence, even modern European regulations Eurocodes (EC) [1]. It is concluded that newer versions of EC will be semi-probabilistic regarding the partial factors, which are now primarily based on deterministic equations. There is a document that is the first attempt to provide rules and regulations for the probabilistic design of structures [2]. There is much resistance against this with the preference being to stay with traditional non-probabilistic codes. Advocates of traditional design methods often say, which is mostly true, that data is too scarce to switch to probabilistic design. However, when there is little known about the action, what remains is purely probabilistic [2]. This article will focus on impact load on bridge substructures. There is a very little information and experiments in this area, so this topic is ideal for the probabilistic approach.

\section{Regulations}

European regulation EN 1991-7 provides strategies and rules for safeguarding buildings and other civil engineering works against identifiable and unidentifiable accidental actions. For bridges, actions (forces) depend upon the type of traffic under the bridge and the consequences of impact. Design values of forces on columns and bearing walls are given in table 1. Index $\mathrm{x}$ refers to the direction of normal travel and $y$ is perpendicular to the direction of normal travel. The force is 0.5 meters above ground for cars and 1.5 meters for lorries.

Table 1: $\quad$ Impact forces according to EN 1991-7.

\begin{tabular}{|c|c|c|}
\hline Category & $\begin{array}{c}\text { Minimum Force } F_{\mathrm{d}, \mathrm{x}} \\
{[\mathrm{kN}]}\end{array}$ & $\begin{array}{c}\text { Minimum Force } F_{\mathrm{d}, \mathrm{y}} \\
{[\mathrm{kN}]}\end{array}$ \\
\hline $\begin{array}{c}\text { Motorways and } \\
\text { country } \\
\text { national roads }\end{array}$ & 1000 & 500 \\
\hline $\begin{array}{c}\text { Country roads in } \\
\text { rural areas }\end{array}$ & 750 & 375 \\
\hline $\begin{array}{c}\text { Roads in urban areas } \\
\text { Court yards and } \\
\text { parking } \\
\text { garages with access } \\
\text { to: }\end{array}$ & 500 & 250 \\
- Cars \\
- Lorries
\end{tabular}




\section{Probabilistic modelling}

The probabilistic approach is defined in part B.9.3.2 of the Eurocode 1 regulations [1] and fully in [2]. The basic model is represented in figure 1. The model for impact constitutes of: potentially colliding objects (vehicles, ships, airplanes) that have an intended course which may be the centre line of a traffic line, the occurrence of a human or mechanical failure (that may lead to deviation), the course of the object after the initial failure, mechanical impact between object and structure [2].

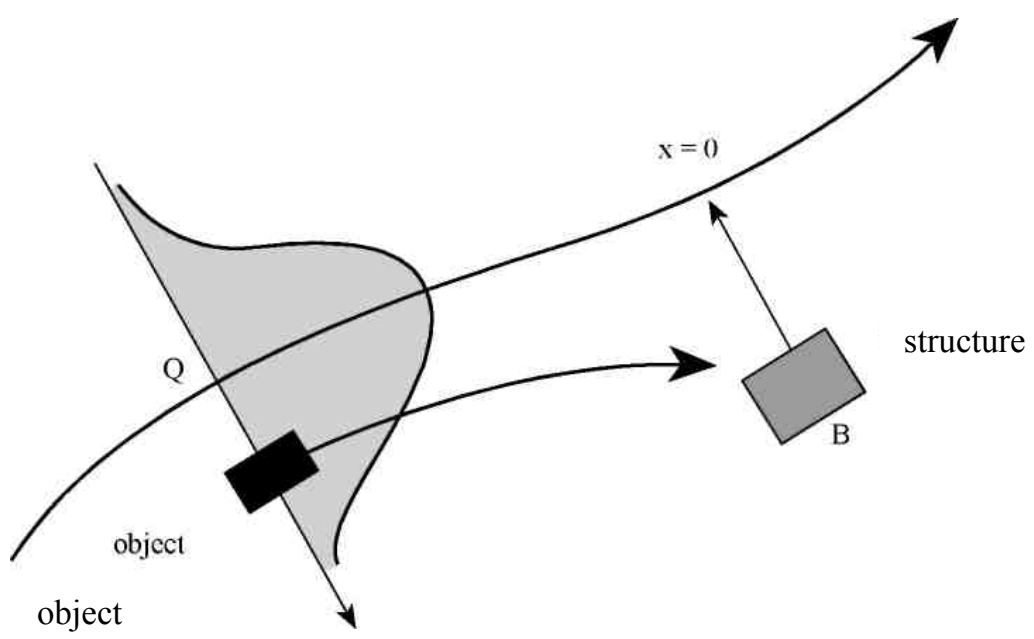

Figure 1: $\quad$ Basic model.

\subsection{Failure probability}

The probability that a single object, while moving in $\mathrm{x}$ direction, suffers from a human or mechanical failure in square $[\mathrm{dx}, \mathrm{dy}]$ is given in eqn. (1).

$$
P_{f q}(x, y) \cdot f_{S}(y) \cdot d y \cdot \lambda(x, t) \cdot d x
$$

$F_{s}(y)$ is the distribution of the initial object position, $P_{f q}(x, y)$ is the probability of structural failure. $\lambda(\mathrm{x}, \mathrm{y})$ is failure intensity as a function of the coordinate $\mathrm{x}$ and time t. This time dependency indicates differences in summer and winter, day and night etc.

The probability of structural failure (for a small probability and constant $\mathrm{n}(\mathrm{t})$ and $\lambda$ ) for a period $T$ can be given by eqn. (2). $T$ is the period under consideration and $\mathrm{n}(\mathrm{t})$ is the number of moving objects per time unit.

$$
P_{f}(T)=n \cdot T \cdot \lambda \iint P_{f q}(x, y) \cdot f_{s}(y) \cdot d y \cdot d x
$$




\subsection{Distribution function for impact loads}

The upper bound for the impact force can be found using "rigid structure" assumption. A colliding object is modelled as an elastic single degree of freedom system, with equivalent stiffness $\mathrm{k}$ and mass $\mathrm{m}$. The maximal force $\mathrm{F}$ is then given by eqn. (3).

$$
F=v \cdot \sqrt{k \cdot m}
$$

Based on eqn. (3) and for small probabilities, the distribution function for the load F (see eqn. (4)) can be found.

$$
P\{F>X\}=P_{f}(T)=n \cdot T \cdot \lambda \iint(v \cdot \sqrt{k \cdot m})>X \cdot f_{s}(y) \cdot d y \cdot d x
$$

\subsection{Impact from vehicles}

We consider a column (or structural member in general) in the vicinity of the road or track. Impact will happen if a vehicle leaves its intended course (see figure 2). The collision force probability distribution based on eqn (4) (neglecting the variability in y direction) is given in eqn. (5), $\mathrm{n}$ is the number of vehicles per time unit, $\mathrm{T}$ is the period under consideration, $\lambda$ is the probability of a vehicle leaving the road, $\Delta \mathrm{x}$ is the part of the road from where the collision may be expected, $v$ is velocity of the vehicle when leaving the track and a is deceleration.

$$
P\{F>X\}=P_{f}(T)=n \cdot T \cdot \lambda \cdot \Delta x \cdot P\left[\sqrt{\left(v^{2}-2 \cdot a \cdot r\right) \cdot k \cdot m}\right]>X
$$
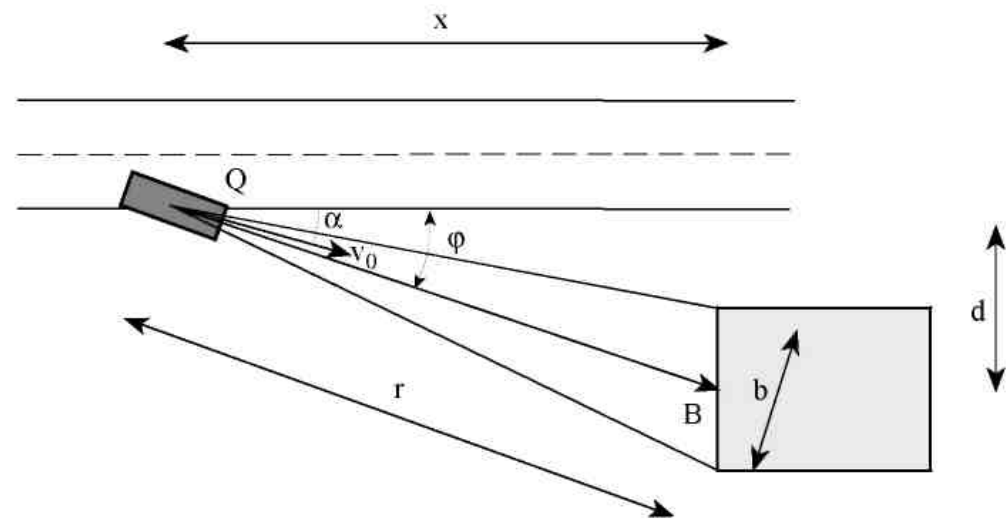

Figure 2: $\quad$ Model for impact from vehicles. 
If we set $n \cdot T \cdot \lambda \cdot \Delta x=1$, we get eqn. (6). This means that in a lifetime of the bridge, one accident will happen.

$$
P\{F>X\}=P_{f}(T)=P\left[\sqrt{\left(v^{2}-2 \cdot a \cdot r\right) \cdot k \cdot m}\right]>X
$$

\section{Probabilistic calculation of impact force}

\subsection{Bridge columns}

For purpose of this article a very simple column will be selected. The column is 5 meters high; and the cross section is $0.6 \times 1.0$ meters with a protective layer of reinforcement of 3 centimetres. This is the middle column of the bridge as shown in figure 3. The concrete is $\mathrm{C} 30 / 37$ and the structural steel is S500/560. As the bridge is designed for seismic load (according to Eurocode regulations), the design axial load in the column is $2668 \mathrm{kN}$ and the non-factored value of the axial load is $1936 \mathrm{kN}$.

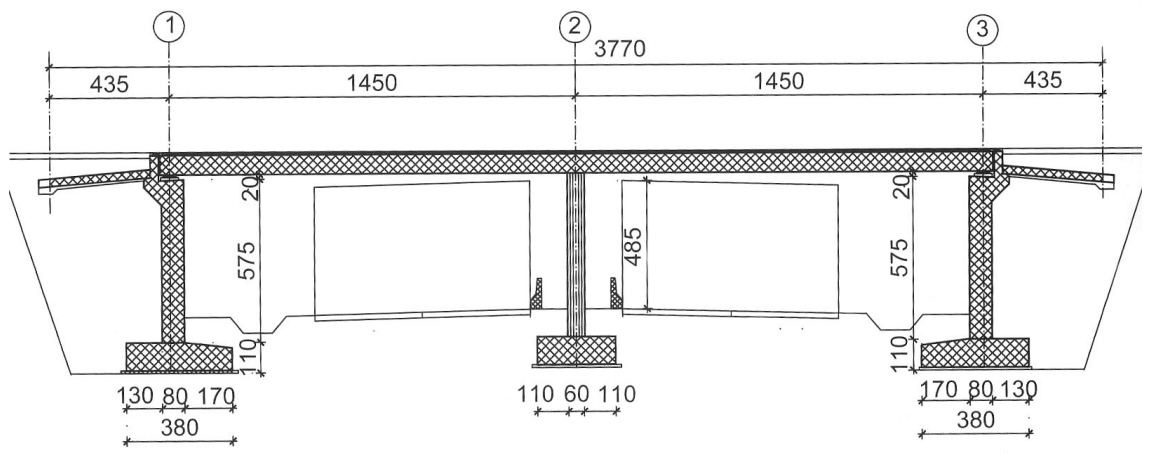

Figure 3: Longitudinal section of the bridge.

\subsection{Limit state equation}

The limit state equation is given in eqn. (8). $M_{r d}$ is the resistance bending moment, $\mathrm{M}_{\mathrm{E}}$ is the bending moment due to actions. It is assumed that during impact a plastic hinge will form at the end of the column. This is only an assumption, but on the other hand, as we are using the rigid body principle when calculating impact force, it would not be feasible to assume otherwise. Based on this, bending resistance $\left(\mathrm{M}_{\mathrm{rd}}\right)$ can be calculated as in eqn. (8). $\mathrm{A}_{\mathrm{s} 1}$ and $\mathrm{A}_{\mathrm{s} 2}$ stand for the area of reinforcement, $\mathrm{f}_{\mathrm{yd}}$ is the yield strength of the steel reinforcement, and $\mathrm{N}_{\mathrm{Ed}}$ is the non-factored axial force in the column. Other labels in the equation are shown in figure 4 . The column is modeled as a simple cantilever beam as in eqn. (9), with impact force F acting at height $h$ of the column.

$$
M_{r d}-M_{E}=0
$$




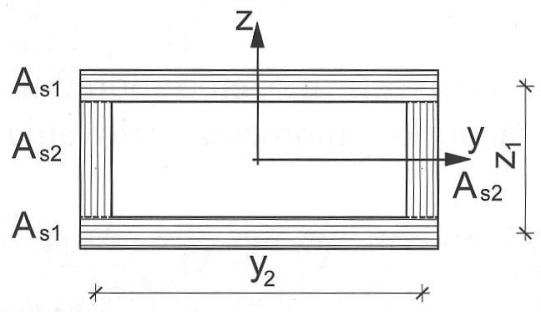

Figure 4: Reinforcement and arm moment.

$$
\begin{gathered}
M_{r d}=A_{s 2} \cdot f_{y d} \cdot y_{2}+2 \cdot A_{s 1} \cdot f_{y d} \cdot \frac{y_{2}}{2}+N_{E d} \cdot \frac{y_{2}}{2} \\
M_{E}=F \cdot h
\end{gathered}
$$

Based on eqns. (6)-(9) the limit state function is given in eqn. (10).

$$
\begin{array}{r}
\gamma_{M} \cdot\left(A_{s 1} \cdot f_{y} \cdot y_{2}\right. \\
\left.+2 \cdot A_{s 1} \cdot f_{y} \cdot \frac{y_{2}}{2}+N_{E d} \cdot \frac{y_{2}}{2}\right), \\
-h \cdot \sqrt{k \cdot m \cdot\left(v^{2}-2 \cdot a \cdot r\right)}=0
\end{array}
$$

It must be noted that $r$ in eqn. (10) can be calculated as in eqn. (11):

$$
r=d / \sin \alpha
$$

In table 2 all base variables are given with their designation, type of probability distribution, mean value and standard deviation. Height of impact force $h$ is set as deterministic and taken as 0.5 meters for cars and 1.5 meters for trucks.

\section{Results of reliability analysis}

Based on data from previous sections, the probabilistic analysis conducted is the first order reliability method (FORM). Only two input variables were subjected to change: vehicle speed and vehicle mass, all others were the same as defined in table 2. The distribution type and standard deviation for these two variables remain the same, but in proportion as given in table 2 . The result of the analysis for this column is given in table 3 . As expected, it is shown that impact from a car with a mean mass of $1000 \mathrm{~kg}$ and corresponding speed cannot result in the failure of the bridge column. Trucks are modeled with a mean mass of $20000 \mathrm{~kg}$ and the corresponding probability of failure is much higher, but for the impact load these probabilities are still very low. The design point for the minimal 
reliability index $(\beta=2.12)$ from table 3 is very interesting. The design point and components of the alpha vector (sensitivity of basic variables) are given in table 4 . The value of the impact force $(\mathrm{F}=2300 \mathrm{kN})$ that can be calculated from table 4 is very interesting. This means that the impact force given in the regulations is greatly underestimated.

Table 2: $\quad$ Base variables for the reliability calculation.

\begin{tabular}{|c|c|c|c|c|}
\hline Variable & Designation & Type & Mean & $\begin{array}{l}\text { Standard } \\
\text { deviation }\end{array}$ \\
\hline$\gamma_{M}$ & Resistance uncertainty & Lognormal & 1 & 0.1 \\
\hline $\mathrm{A}_{\mathrm{s} 1}$ & $\begin{array}{l}\text { Area of reinforcement } \\
\qquad \mathrm{s} 1\left[\mathrm{~cm}^{2}\right]\end{array}$ & Normal & 48 & 2.4 \\
\hline $\mathrm{A}_{\mathrm{s} 2}$ & $\begin{array}{c}\text { Area of reinforcement } \\
\mathrm{s} 2\left[\mathrm{~cm}^{2}\right]\end{array}$ & Normal & 30 & 1.5 \\
\hline$f_{y}$ & Yield strength $[\mathrm{kN} / \mathrm{cm} 2]$ & Lognormal & 50 & 2.5 \\
\hline Variable & Designation & Type & Mean & $\begin{array}{l}\text { Standard } \\
\text { deviation }\end{array}$ \\
\hline $\mathrm{y}_{2}$ & Arm moment $[\mathrm{cm}]$ & Normal & 74 & 3.7 \\
\hline $\mathrm{N}_{\mathrm{Ed}}$ & Axial force $[\mathrm{kN}]$ & Lognormal & 1936 & 193.6 \\
\hline $\mathrm{k}$ & $\begin{array}{c}\text { Vehicle stiffness } \\
{[\mathrm{kN} / \mathrm{m}]}\end{array}$ & Lognormal & 300 & 60 \\
\hline $\mathrm{m}$ & Vehicle mass $[\mathrm{kg}]$ & Normal & $\begin{array}{c}1000 \\
(20000)\end{array}$ & $\begin{array}{c}250 \\
(10000) \\
\end{array}$ \\
\hline $\mathrm{V}$ & Vehicle speed $[\mathrm{kmh} / \mathrm{h}]$ & Lognormal & $\begin{array}{l}130 \\
(80)\end{array}$ & $\begin{array}{c}20 \\
(10)\end{array}$ \\
\hline $\mathrm{a}$ & Deceleration $[\mathrm{m} / \mathrm{s}]$ & Lognormal & 4 & 1.3 \\
\hline$\alpha$ & Angle of collision $\left[{ }^{\circ}\right]$ & Deterministic & 10 & - \\
\hline $\mathrm{r}$ & $\begin{array}{c}\text { Distance from leaving } \\
\text { point to impact [m] }\end{array}$ & Deterministic & 23 & - \\
\hline $\mathrm{h}$ & $\begin{array}{l}\text { Height of impact force } \\
{[\mathrm{m}]}\end{array}$ & Deterministic & $\begin{array}{c}0.5 \\
(1.5)\end{array}$ & - \\
\hline
\end{tabular}

Table 3: $\quad$ Vehicle speed and mass with corresponding reliability index.

\begin{tabular}{|c|c|c|c|}
\hline $\begin{array}{c}\text { Mean vehicle } \\
\text { speed } \\
{[\mathrm{km} / \mathrm{h}]}\end{array}$ & $\begin{array}{c}\text { Mean vehicle } \\
\text { mass } \\
{[\mathrm{kg}]}\end{array}$ & $\begin{array}{c}\text { Reliability index } \\
\beta\end{array}$ & $\begin{array}{c}\text { Probability of } \\
\text { failure } \\
\mathrm{p}_{\mathrm{f}}\end{array}$ \\
\hline 130 & 1000 & 19.5 & $1.38 \mathrm{e}-84$ \\
\hline 150 & 1000 & 12.1 & $4.25 \mathrm{e}-34$ \\
\hline 80 & 20000 & 1.77 & $3.8 \mathrm{e}-2$ \\
\hline 60 & 20000 & 3.17 & $7.62 \mathrm{e}-4$ \\
\hline
\end{tabular}


Table 4: $\quad$ Base variables, design points and sensitivities.

\begin{tabular}{|c|c|c|c|}
\hline Variable & Designation & Design point & $\begin{array}{c}\text { Alpha vector } \\
\text { (Sensitivity } \alpha \text { i) }\end{array}$ \\
\hline$\gamma_{\mathrm{M}}$ & Resistance uncertainty & 0.94 & 0.346 \\
\hline $\mathrm{A}_{\mathrm{s} 1}$ & $\begin{array}{c}\text { Area of reinforcement } \\
\mathrm{s} 1\end{array}$ & 47.64 & 0.086 \\
\hline $\mathrm{A}_{\mathrm{s} 2}$ & $\begin{array}{c}\text { Area of reinforcement } \\
\text { s2 }\end{array}$ & 29.86 & 0.054 \\
\hline $\mathrm{f}_{\mathrm{y}}$ & Yield strength of steel & 49.327 & 0.139 \\
\hline $\mathrm{y}_{2}$ & Arm moment & 72.84 & 0.176 \\
\hline $\mathrm{N}_{\mathrm{Ed}}$ & Axial force & 1903 & 0.069 \\
\hline $\mathrm{k}$ & Vehicle stiffness & 331.90 & -0.344 \\
\hline $\mathrm{m}$ & Vehicle mass & 30190 & -0.574 \\
\hline $\mathrm{v}$ & Vehicle speed & 90.18 & -0.578 \\
\hline $\mathrm{a}$ & Deceleration & 3.43 & 0.185 \\
\hline
\end{tabular}

\section{Conclusion}

In this article, deterministic and probabilistic methods for the determination of impact forces are given. It is shown that regulations (EN 1991-7) can very much underestimate the value of impact force. What is yet to be determined is the percentage of kinetic energy that is transferred during impacts. The values of forces obtained from probabilistic analysis are based on the simple impact force model (rigid structure) that can, in general, overestimate the value of the impact force. As deterministic methods are also based on this model, values must be taken with great care. What is beyond doubt is that values of forces obtained for probabilistic model are generally higher. The probability of failure, which cannot be given when performing deterministic calculations, is very interesting. In this article an example of the impact on a bridge column is given. The column has very low probabilities of failure. This is primarily because of traffic and seismic loads subjected specifically to this bridge. If this were a pedestrian bridge, the columns would be much thinner, so impact load could be the most important consideration when designing bridge columns.

\section{References}

[1] Pr EN 1991: Eurocode 1: Action on structures - part 1-7: General actions accidental actions, European Committee for Standardization, Brussels, 2004.

[2] Faber, M. H., Probabilistic model code, JCSS Publication, 2001.

[3] Radic, J., Puz, G., Mandic, A., Designing of bridges, Faculty of Civil Engineering, Zagreb, 2005.

[4] Androic, B., Dujmovic, D., Džeba, I., Reliability engineering 1, IA Projektiranje, Zagreb, 2006. 
[5] EN 1990: Eurocode 0 - Basis of structural design, European committee for standardization, Brussels, 2001.

[6] Milčic, V., Peros, B., Introduction to reliability of structures, University of Split, Faculty of Civil Engineering, Split, 2003.

[7] Mihanovic, A., Dynamics of Structures, University of Split - Faculty of Civil Engineering, 1995. 